\title{
Experimental Measurements and Modeling of Vapor-Liquid Equilibrium of Isobutane and Ethyl Mercaptan Binary System
}

\author{
Esther Neyrolles, Alain Valtz, Eric Boonaert and Christophe Coquelet ${ }^{\star}$ \\ Mines ParisTech PSL University, Fontainebleau, France
}

\section{ARTICLE INFO}

Article Type: Research Article

Keywords:

Isobutane

Oil and gases

Ethyl mercaptan

Equation of state

Vapor-liquid equilibrium

\section{Timeline:}

Received: June 06, 2021

Accepted: July 27, 2021

Published: September 03, 2021

Citation: Neyrolles E, Valtz A, Boonaert E, Coquelet C. Experimental Measurements and Modeling of VaporLiquid Equilibrium of Isobutane and Ethyl Mercaptan Binary System. Int J Petrol Technol. 2021; 8: 43-54.

DOl: https://doi.org/10.15377/2409-787X.2021.08.4

\begin{abstract}
In this work, new isothermal experimental data of vapor-liquid equilibrium of the isobutane and ethyl mercaptan binary system are presented. The pressure and temperature conditions are up to $1 \mathrm{MPa}$ and between 298 and 343K. The experimental apparatus is based on a "static-analytic method" specially developed for low-pressure measurements. Two online capillary samplers are used to take vapor and liquid samples that are analyzed with a gas chromatograph. The classical Peng Robinson Equation of State is used to correlate the experimental data. The van Ness test is used to check the consistency of the data. The measured data are also compared to predicted values from two predictive models, and a good agreement is found between the PSRK UNIFAC and the PPR78 models and the experimental measurements.
\end{abstract}

\footnotetext{
*Corresponding Author

Email: christophe.coquelet@mines-paristech.fr

Tel: +33682220592
}

(C2021 Neyrolles et al.; Published by Avanti Publishers. This is an open access article licensed under the terms of the Creative Commons Attribution Non-Commercial License which permits unrestricted, non-commercial use, distribution and reproduction in any medium, provided the work is properly cited. (http://creativecommons.org/licenses/by-nc/4.0/) 


\section{Introduction}

One of the challenges concerning the use of natural gas or petroleum is the presence of sulfur compounds and, in particular of mercaptans (thiols) in large quantities. These sulfur components need to be removed. In the gas processing industry, mercaptans are removed by the acid gas removal (hydrogen sulfide and carbon dioxide) operation unit [1]. After this treatment, some mercaptans not removed are concentrated in hydrocarbon condensates and are therefore present in the fractionation train composed of a series of distillation columns: debutaniser, de-propaniser, and de-ethaniser. We can also mention that mercaptans are not the only contaminants; it is possible to found traces of $\mathrm{H}_{2} \mathrm{~S}, \mathrm{CO}_{2}, \mathrm{CS}_{2}, \mathrm{COS}$, sulfides, disulfides, $\mathrm{N}_{2}, \mathrm{H}_{2} \mathrm{O}$, and $\mathrm{MeOH}$ [2]. In the petroleum industry, desulfurization operation units are also considered [3], and sulfur removal represents a major economic challenge for the petroleum refining industry [4]. The knowledge of equilibrium properties and phase diagrams is essential. For example, a better understanding of how the organic sulfur compounds are distributed during all of the steps of the production of natural gas processing fractionation systems is very important for the design of the distillation column.

One of the solutions is to measure the thermodynamic properties of hydrocarbons and mercaptans systems in the temperature and pressure conditions of the process. For example, the vapor-liquid equilibrium (VLE) study of the phase equilibria of a system allows us to classify them following the van Konynenburg and Scott [5] classification. In their classification, van Konynenburg and Scott described at least 5 types of diagrams for a binary mixture. The classification of the phase diagram of a binary system: hydrocarbon-sulfur compound provides information on the interaction between the two molecules. It can also be helpful for the selection of a thermodynamic model to be used for the data treatment. It is difficult to obtain experimental reliable thermodynamic data such as VLE data for a system containing sulfur compounds like hydrogen sulfide and mercaptan because of their acute toxicity and high volatility. The Centre of Thermodynamics of Processes (CTP) of Mines Paris, during the last years, has studied and measured VLE data of numerous binary and ternary systems involving hydrocarbons and mercaptans [6-9].

In this paper, the binary system studied is composed of isobutane and ethyl mercaptan (ethanethiol), and VLE data are measured from 298 to $343 \mathrm{~K}$. To correlate the data, the classical Peng Robinson Equation of State (PR78 EoS) [10] is used, and the results are compared with two calculations obtained with two predictive models: PPR78 [11] and PSRK UNIFAC [12].

To the knowledge of the authors, no vapor-liquid equilibrium data of the isobutane and ethyl mercaptan binary system were found in the open literature using ThermoLit (NIST Literature Report Builder for Thermochemical Property Measurements [13]). The study of this system was made to fill the gap in the literature on this binary system. In Table 1, the literature studies on binary systems with sulfur compounds and butane (isobutane $\left(\mathrm{iC}_{4}\right)$ and n-butane $\left(\mathrm{nC}_{4}\right)$ ) is reported. In 2020, we measured new VLE data concerning the n-butane and ethyl mercaptan binary system (Boonaert et al. [8]). We can also observe that there is a lack of experimental VLE data for binary systems with isobutane, except with $\mathrm{H}_{2} \mathrm{~S}$. This is one of the reasons why we present in this paper new VLE data concerning the binary system isobutane and ethyl mercaptan. We can also mention that further experimental measurements must be done in the future to complete the matrix presented in Table 1. In addition, these new experimental data can be used to feed databases, for example, the NIST database or the Dortmund Data Bank (DBB), but also to improve thermodynamic models used in process simulators.

\section{Materials and Methods}

\subsection{Materials}

The chemical compounds used for the experimental measurements are presented in Table 2 . Isobutane has a certified purity of 99.95 vol\%, and ethyl mercaptan has a certified purity of 99 vol\%. 
Table 1: Literature matrix of data for VLE of binary systems containing butane and sulfur compounds (in red: the system chosen for this study).

\begin{tabular}{|c|c|c|c|}
\hline Sulfur compound & Cas number & $\mathrm{nC}_{4}$ & $\mathrm{iC}_{4}$ \\
\hline $\mathrm{H}_{2} \mathrm{~S}$ & 7783-06-04 & [14-17] & {$[16,18]$} \\
\hline $\mathrm{MM}$ & 74-93-1 & [19] & [20] \\
\hline EM & $75-8-1$ & {$[8,21]$} & $N D^{a}$ \\
\hline $\mathrm{nPM}$ & $107-03-9$ & {$[22]$} & ND \\
\hline IPM & $75-33-2$ & ND & ND \\
\hline $\mathrm{nBM}$ & $109-79-5$ & ND & ND \\
\hline IBM & $513-44-0$ & [23] & ND \\
\hline tBM & $75-66-1$ & [24] & {$[24]$} \\
\hline DMS & $75-18-3$ & {$[25]$} & {$[25]$} \\
\hline EMS & $624-89-5$ & ND & ND \\
\hline DMDS & $624-92-0$ & [26] & {$[26]$} \\
\hline $\cos$ & $463-58-1$ & [23] & ND \\
\hline $\mathrm{CS}_{2}$ & $75-15-0$ & ND & ND \\
\hline
\end{tabular}

$\mathrm{H}_{2} \mathrm{~S}$ : hydrogen sulfide, COS: carbonyl sulfide, MM: methyl mercaptan, EM: ethyl mercaptan, $\mathrm{CS}_{2}$ : carbon disulfide, nPM: n-propyl mercaptan IPM: isopropyl mercaptan, nBM: n-butyl mercaptan, IBM: isobutyl mercaptan, tBM: tert-butyl mercaptan, DMS: dimethyl sulfide, EMS: ethyl methyl sulfide, DMDS: dimethyl disulfide, $\mathrm{nC}_{4}$ : $\mathrm{n}$-butane, $\mathrm{iC}_{4}$ : isobutane.

${ }^{a}$ ND: No Data found.

Table 2: Presentation of the compounds used for this study (purities and suppliers).

\begin{tabular}{|c|c|c|c|}
\hline Chemicals & Cas number & Purity (GC ${ }^{\text {a) }}$ & Supplier \\
\hline \hline ethyl mercaptan (EM) & $75-08-1$ & $\geq 99$ vol\% & Acros \\
\hline isobutane $\left(\mathrm{iC}_{4}\right)$ & $75-28-5$ & 99.95 vol\% & Air Liquide \\
\hline
\end{tabular}

${ }^{a} \mathrm{GC}:$ Gas Chromatograph

The critical temperatures $\left(T_{c}\right)$, pressures $\left(P_{c}\right)$, and acentric factors $(\omega)$ for isobutane and ethyl mercaptan are given in Table 3. The properties are the ones given by the Simulis Thermodynamics ${ }^{\mathrm{TM}}$ software from PROSIM (France).

Table 3: Properties of isobutane and ethyl mercaptan pure components from Simulis Thermodynamics ${ }^{\mathrm{TM}}$.

\begin{tabular}{|c|c|c|c|c|}
\hline Component & Formula & $\mathbf{T}_{\mathrm{c}}(\mathrm{K})$ & $\mathbf{P}_{\mathrm{c}}(\mathrm{MPa})$ & $\omega$ \\
\hline isobutane & $\mathrm{C}_{4} \mathrm{H}_{10}$ & 407.80 & 3.64 & 0.183521 \\
\hline ethyl mercaptan/ethanethiol & $\mathrm{C}_{2} \mathrm{H}_{6} \mathrm{~S}$ & 499.15 & 5.49 & 0.187751 \\
\hline
\end{tabular}

\subsection{Methods}

An experimental technique based on the static analytic method is used in this study. The equipment was previously presented and described by Boonaert et al. [8], Zhang et al. [27], and Théveneau et al. [28]. A flow diagram of the experimental apparatus is presented in Fig. 1. 


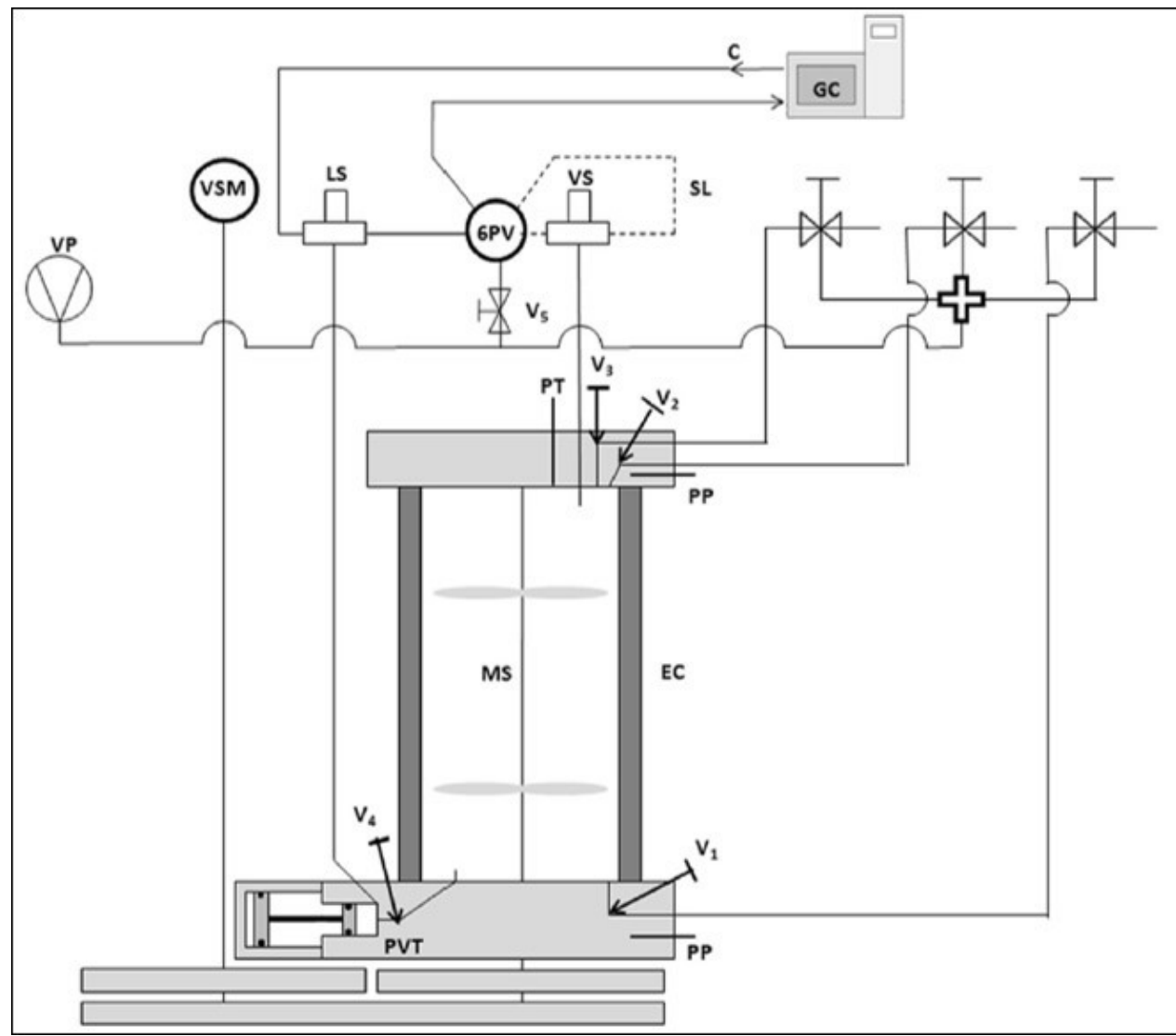

Figure 1: Flow diagram of the low-pressure apparatus, from Zhang et al. [27]: "EC: Equilibrium Cell, GC: Gas Chromatograph, LS: Liquid sampler, VS: Vapor sampler, Vi: Valves, PP: Platinum probe, VSM: Variable Speed Motor, MS: Magnetic stirrer, SL: Sample loop, C: Carrier gas flow, PVT: a chamber for the liquid phase sampling, PT: Pressure Transducer, VP: Vacuum pump, 6PV: 6-port sample injection valve".

Since the apparatus has already been described in previously submitted papers, only a brief description is presented here. The approximate volume of the equilibrium cell is $100 \mathrm{~cm}^{3}$ with a sapphire tube to see the mixture. The equilibrium cell is immersed in a Lauda Proline RP $3530 \mathrm{C}$ liquid bath $\left( \pm 0.01{ }^{\circ} \mathrm{C}\right)$. To reach the vaporliquid equilibrium faster, a magnetic stirrer is activated. A Keller pressure transducer is used $\left(\mathrm{P}_{\max }=0.1 \mathrm{MPa}\right)$ to measure the pressure. The pressure transducer is calibrated with a numerical standard (Desgranges \& Huot, $n^{\circ}$ 24610 , France). The accuracy was estimated to be $\pm 200 \mathrm{~Pa}$ after calibration. Two $100 \Omega$ platinum resistance thermometer probes are used to measure the temperature at the upper and lower flanges of the equilibrium cell. The gradient of temperature between the vapor and liquid phases is determined and controlled. A $25 \Omega$ reference platinum probe (Tinsley, France) is used to calibrate the platinum probes. The accuracy of the two platinum probes is evaluated to be within $\pm 0.02 \mathrm{~K}$. Two ROLSI ${ }^{\circledR}$ capillary samplers are used to sample vapor and liquid phases. To carry out a sample at low pressure $\left(P_{\max }<0.3 \mathrm{MPa}\right.$, the approximate pressure of the GC carrier gas), two special systems were developed by Zhang et al. [27]. For the sampling of the liquid phase, the modification of the sampling device composed by a PVT chamber and ROLSI ${ }^{\circledR}$ capillary sampler is the subject of a patent [29].

The methodology followed to obtain VLE data is described in Fig. 2. The following section also describes the methodology in more detail:

First, the equilibrium cell is placed under vacuum. Then it is immersed in the bath, set to work at the desired temperature. The stirring of the equilibrium cell is activated. The ethyl mercaptan is then introduced through the $\mathrm{V} 1$ valve (with a sufficient volume to be able to take a liquid sample). The isobutane is introduced through the V2 valve. When the cell is at equilibrium, therefore $P$ and $T$ constants, several samples are taken out by the capillary samplers, at least four times for the liquid and vapor phases, respectively. Then, additional isobutane is 
introduced, and the previous steps are repeated to cover the entire molar fraction range of isobutane. Finally, the last step concerns the emptying of the equilibrium cell and its cleaning with nitrogen. The equipment is put under vacuum to begin measuring a new isotherm of the binary system.

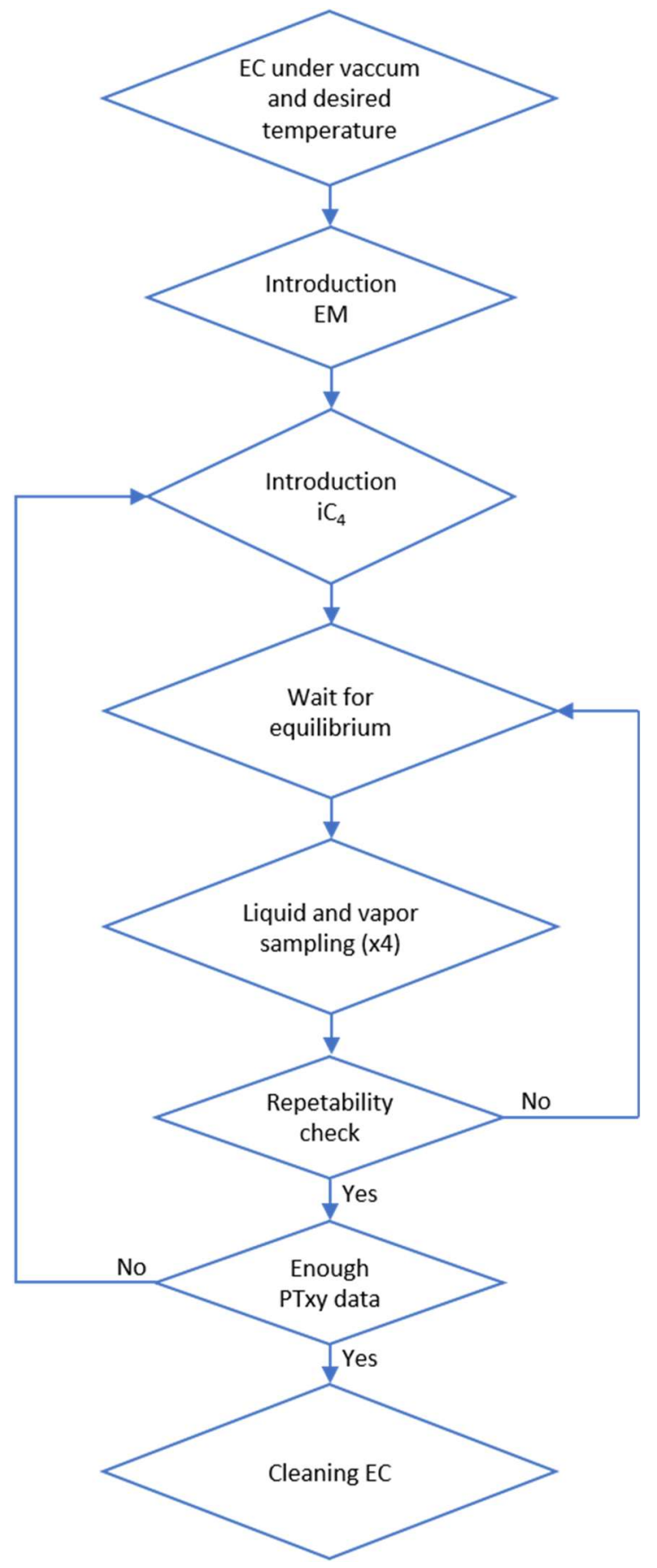

Figure 2: Flowchart of the experimental methodology to measure VLE data of isobutane and ethyl mercaptan binary system; EC: equilibrium cell, EM: ethyl mercaptan, $\mathrm{iC}_{4}$ : isobutane.

The gas chromatograph is equipped with a packed column (2-meters long RT XL sulfur, sulfinert tubing, 100/120 Mesh, $2 \mathrm{~mm}$ ID column). Samples are analysed by the Thermal Conductivity Detector (TCD), calibrated by injection of known volumes of each chemical using a GC syringe. The relative mole numbers accuracies are $\pm 3.2 \%$ for ethyl mercaptan and $\pm 1.9 \%$ for isobutane, respectively. Eq. 1 is used to estimate the uncertainty of the mixture composition of each component. 


$$
u_{\text {calib }}\left(x_{i}\right)=\sqrt{\sum_{j}^{n c o m p}\left(\frac{\partial x_{i}}{\partial n_{j}}\right)_{j \neq i}^{2} u^{2}\left(n_{j}\right)}
$$

where $u_{\text {calib }}\left(x_{i}\right)$ is the uncertainty from calibration of $x_{i}, x_{i}$ is the molar fraction of component $i$, and $n_{j}$ is the number of moles of component $\mathrm{j}$.

For a binary system, Eq. 2 is considered.

$$
u_{\text {calib }}\left(x_{1}\right)=x_{1}\left(1-x_{1}\right) \sqrt{\left(\frac{u\left(n_{1}\right)}{n_{1}}\right)^{2}+\left(\frac{u\left(n_{2}\right)}{n_{2}}\right)^{2}}
$$

where $\frac{u\left(n_{i}\right)}{n_{i}}$ is the mole number relative uncertainty.

The maximum calibration uncertainty on mole fraction is given at $x_{1}=0.5$ : $u_{\max }(x)=0.0082$. Type $B$ uncertainty is considered. For each experimental data, between 4 to 8 samples are carried out for each phase. Therefore, the reported data is the average of these samples. The values are reported along with relative standard deviation (noted $\left.u_{r e p}\left(x_{i}\right)\right)$. The final uncertainty on the molar composition $\left(u\left(x_{i}\right)\right)$ is obtained considering Eq. 3.

$$
u\left(x_{i}\right)=\sqrt{u_{\text {calib }}\left(x_{i}\right)^{2}+u_{\text {rep }}\left(x_{i}\right)^{2}}
$$

\section{Results and Discussion}

\subsection{Experimental Results and Modeling}

The experimental molar fractions of isobutane in the liquid phase $\left(x_{1}\right)$ and vapor phase $\left(y_{1}\right)$ at different pressures (between 0.08 and $1.02 \mathrm{MPa}$ ) and at 298, 313, 328, and $342 \mathrm{~K}$ are presented in Table 4.

The PR78 EoS involving the original alpha function with the classical van der Waals mixing rules is applied to correlate the experimental data. The software used is Simulis Thermodynamics ${ }^{\mathrm{TM}}$ developed by PROSIM (Toulouse, France). The calculations are based on a bubble pressure algorithm. The objective function (F), given in Eq. 4, is minimized to adjust the binary interaction parameter (BIP) at each temperature. The adjusted binary interaction parameters and the objective function (F) obtained are presented in Table $\mathbf{5}$.

$$
F=\frac{100}{N}\left[\sum_{1}^{N}\left(P_{\exp }-P_{\text {cal }}\right)^{2}+\sum_{1}^{N}\left(y_{\text {exp }}-y_{\text {cal }}\right)^{2}\right]
$$

Where $N$ is the number of data points, $P_{\text {exp }}$ is the experimental pressure, $P_{\text {cal }}$ is the calculated pressure, $y_{\exp }$ is the experimental gaseous molar fraction, $\mathrm{y}_{\mathrm{cal}}$ is the calculated gaseous molar fraction.

The experimental and modeling VLE data are presented in Fig. 3, i.e., the experimental pressure as a function of the isobutane mole liquid $\left(x_{1}\right)$ and vapor $\left(y_{1}\right)$ fractions at each temperature. The relative volatility $\left(a_{12}\right)$ according to the isobutane liquid molar fraction $\left(\mathrm{x}_{1}\right)$ at each temperature is presented in Fig. $\mathbf{4}$. We can classify this system as type I according to van Konynenburg and Scott classification [5].

The relative volatilities displayed in Fig. $\mathbf{4}$ followed an exponential type trend and allowed us to validate the quality of the experimental data (Mathias, 2017 [30]). The binary interaction parameter $\left(\mathrm{k}_{\mathrm{ij}}\right)$ as a function of the temperature is plotted in Fig. 5. Eq. (5) gives the temperature dependency of the BIP $k_{i j}$ between 298 and $343 \mathrm{~K}$.

$$
k_{i j}=-8.7702 \times 10^{-6} T^{2}+5.5334 \times 10^{-3} T-8.3410 \times 10^{-1}
$$


Table 4: Experimental liquid $\left(x_{1}\right)$ and vapor $\left(y_{1}\right)$ mole fractions of isobutane in the system isobutane (1) + ethyl mercaptan (2) with their uncertainties $\mathrm{u}\left(\mathrm{x}_{1}\right)$ and $\mathrm{u}\left(\mathrm{y}_{1}\right)$.

\begin{tabular}{|c|c|c|c|c|c|c|}
\hline P (MPa) & $n^{a}$ & $x_{1}$ & $u\left(x_{1}\right)$ & $\mathrm{n}^{\mathrm{a}}$ & $y_{1}$ & $u\left(y_{1}\right)$ \\
\hline \multicolumn{7}{|c|}{$298.00 \mathrm{~K}$} \\
\hline 0.080 & 7 & 0.0120 & 0.0010 & 5 & 0.1109 & 0.0020 \\
\hline 0.149 & 6 & 0.1379 & 0.0063 & 5 & 0.5655 & 0.0054 \\
\hline 0.178 & 5 & 0.2078 & 0.0032 & 5 & 0.6610 & 0.0073 \\
\hline 0.208 & 6 & 0.3011 & 0.0073 & 6 & 0.7352 & 0.0039 \\
\hline 0.240 & 5 & 0.4357 & 0.0082 & 6 & 0.7957 & 0.0032 \\
\hline 0.279 & 6 & 0.6273 & 0.0072 & 6 & 0.8634 & 0.0025 \\
\hline 0.331 & 5 & 0.8836 & 0.0029 & 6 & 0.9514 & 0.0010 \\
\hline \multicolumn{7}{|c|}{$313.01 \mathrm{~K}$} \\
\hline 0.501 & 5 & 0.8878 & 0.0033 & 5 & 0.9466 & 0.0011 \\
\hline 0.477 & 7 & 0.8261 & 0.0028 & 5 & 0.9228 & 0.0014 \\
\hline 0.443 & 5 & 0.7077 & 0.0039 & 6 & 0.8789 & 0.0021 \\
\hline 0.379 & 4 & 0.4926 & 0.0067 & 6 & 0.8027 & 0.0032 \\
\hline 0.141 & 6 & 0.0200 & 0.0013 & 5 & 0.1492 & 0.0024 \\
\hline 0.208 & 5 & 0.0994 & 0.0041 & 5 & 0.4632 & 0.0048 \\
\hline 0.257 & 5 & 0.1742 & 0.0042 & 5 & 0.5918 & 0.0046 \\
\hline 0.316 & 5 & 0.2948 & 0.0040 & 5 & 0.7017 & 0.0040 \\
\hline \multicolumn{7}{|c|}{$327.98 \mathrm{~K}$} \\
\hline 0.456 & 5 & 0.2912 & 0.0049 & 5 & 0.6585 & 0.0043 \\
\hline 0.360 & 5 & 0.1555 & 0.0032 & 5 & 0.5180 & 0.0048 \\
\hline 0.278 & 5 & 0.0723 & 0.0043 & 5 & 0.3383 & 0.0043 \\
\hline 0.528 & 5 & 0.4302 & 0.0072 & 6 & 0.7438 & 0.0036 \\
\hline 0.610 & 5 & 0.6073 & 0.0081 & 5 & 0.8230 & 0.0028 \\
\hline 0.690 & 5 & 0.8091 & 0.0066 & 8 & 0.9031 & 0.0017 \\
\hline 0.726 & 5 & 0.8864 & 0.0024 & 5 & 0.9408 & 0.0012 \\
\hline \multicolumn{7}{|c|}{$342.98 \mathrm{~K}$} \\
\hline 1.019 & 5 & 0.8828 & 0.0021 & 5 & 0.9355 & 0.0012 \\
\hline 0.989 & 5 & 0.8419 & 0.0028 & 7 & 0.9144 & 0.0015 \\
\hline 0.891 & 5 & 0.6798 & 0.0048 & 5 & 0.8403 & 0.0026 \\
\hline 0.414 & 5 & 0.0761 & 0.0025 & 6 & 0.3115 & 0.0041 \\
\hline 0.637 & 5 & 0.2784 & 0.0061 & 6 & 0.6001 & 0.0046 \\
\hline 0.749 & 5 & 0.4333 & 0.0057 & 5 & 0.7177 & 0.0039 \\
\hline
\end{tabular}

an: number of samples

Expanded uncertainty $(k=2) u(T)=0.02 \mathrm{~K}, \mathrm{u}(\mathrm{P})=0.0002 \mathrm{MPa}$

Table 5: Binary interaction parameter ( $\left.\mathrm{k}_{12}\right)$ and $\mathrm{F}$ (from Eq. 4) at 298, 313, 328 and $343 \mathrm{~K}$.

\begin{tabular}{|c|c|c|}
\hline $\mathbf{T}(\mathbf{K})$ & $\mathbf{k}_{\mathbf{1 2}}$ & $\mathbf{F}$ \\
\hline \hline 298.00 & 0.0360 & 0.0006 \\
\hline 313.01 & 0.0388 & 0.0008 \\
\hline 327.98 & 0.0372 & 0.0004 \\
\hline 342.98 & 0.0321 & 0.0006 \\
\hline
\end{tabular}




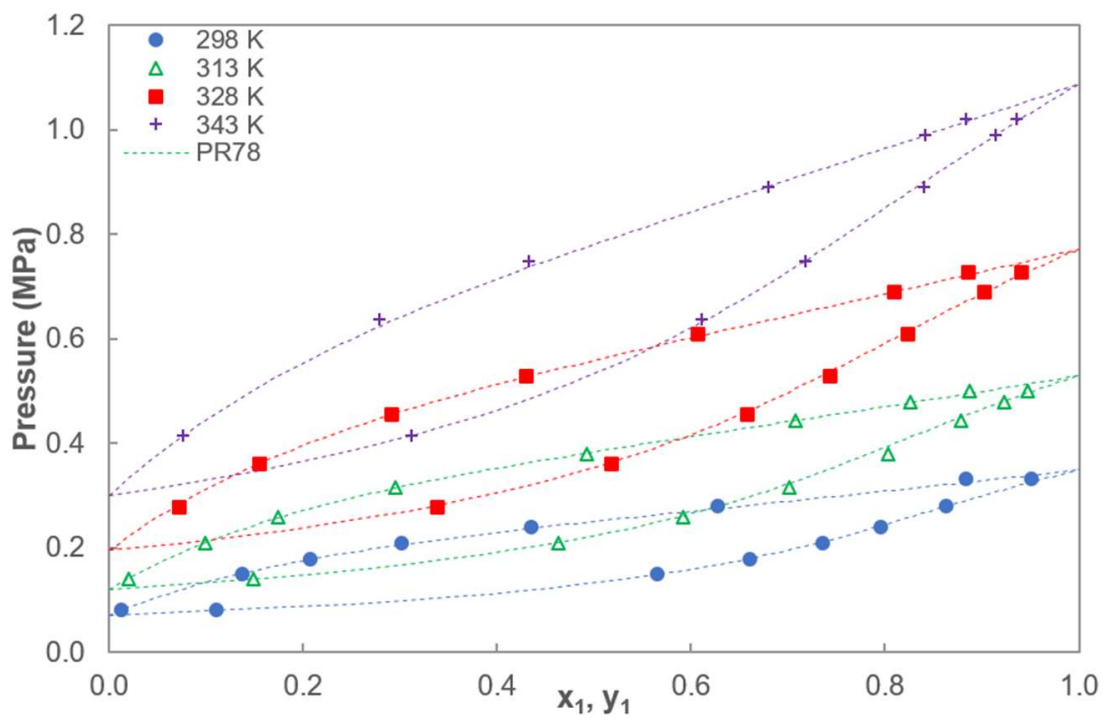

Figure 3: Pressure as a function of isobutane mole fraction in the isobutane + ethyl mercaptan binary system at different temperatures; •: 298 K, $\Delta: 313$ K, $n: 328$ K, +: 343 K. Dashed line: calculated with PR78 EoS and classical mixing rule with parameters from Table 4.

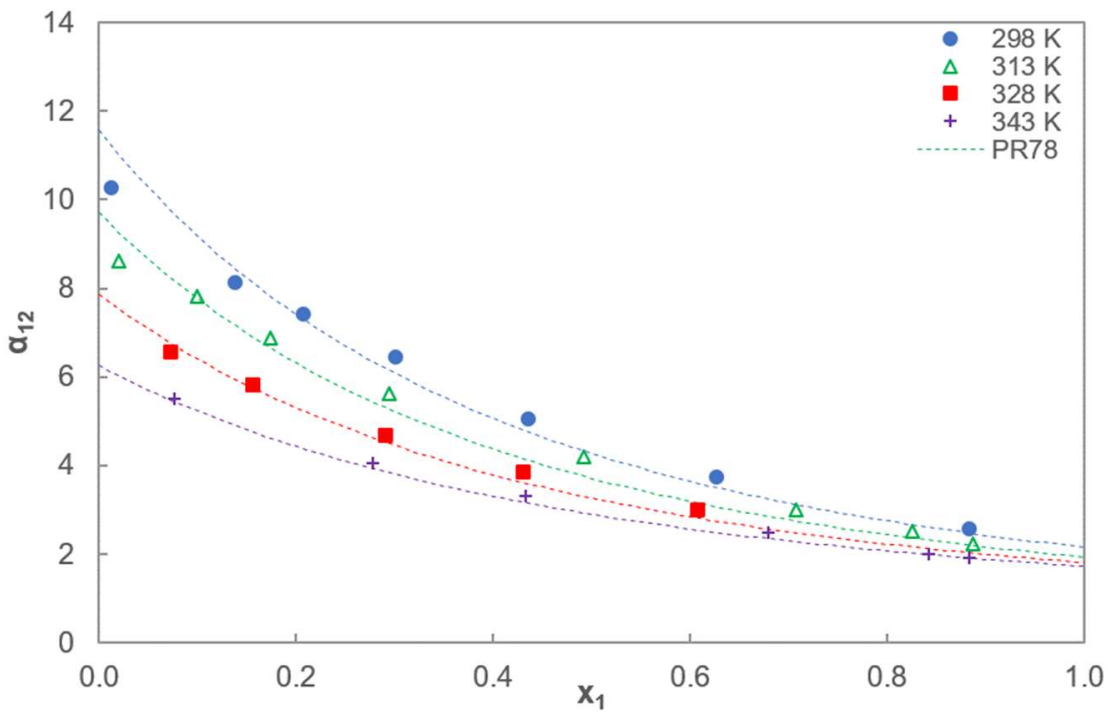

Figure 4: Relative volatility of the isobutane + ethyl mercaptan binary system according to the isobutane molar fraction. •: 298 K, $\Delta: 313 \mathrm{~K}, \mathbf{n}: 328 \mathrm{~K},+: 343 \mathrm{~K}$. Dashed line: calculated with PR78 EoS and classical mixing rule with parameters from Table 4.

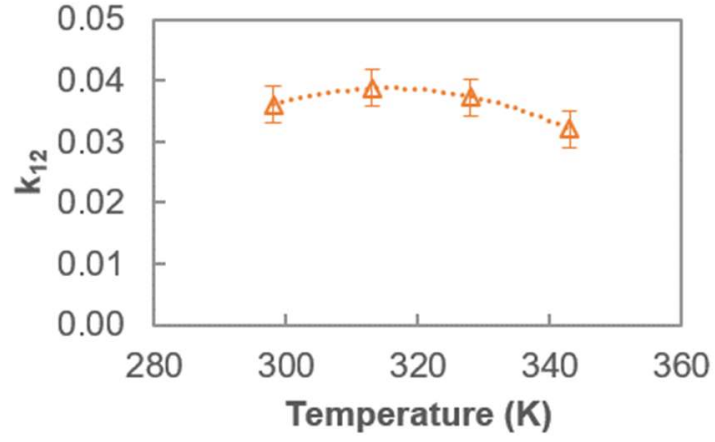

Figure 5: Evolution of $\mathrm{k}_{\mathrm{ij}}$ according to the temperature; error bar $=0.003$. 


\subsection{Consistency test and comparison with two predictive models}

Information about the agreement between model and experimental are calculated using Mean Relative Deviation (MRDU), and the biasU, as defined in Eqs. 6 and 7. These indicator values are presented in Table 6.

$$
\begin{gathered}
\text { MRDU }=\frac{100}{N} \sum\left|\frac{U_{\text {cal }}-U_{\text {exp }}}{U_{\text {exp }}}\right| \\
\text { BiasU }=\frac{100}{N} \sum \frac{U_{\text {exp }}-U_{\text {cal }}}{U_{\text {exp }}}
\end{gathered}
$$

Where $U_{\text {cal }}$ is the calculated pressure $(P)$ or the calculated gaseous molar fraction $\left(y_{1}\right)$ and $U_{\exp }$ is the experimental pressure or the experimental gaseous molar fraction.

Table 6: MRDU (from Eq 6), BiasU (from Eq 7), and van Ness test (from Eqs 8 and 9) between the experimental VLE isobutane + ethyl mercaptan data and PR78 EoS modeling at $298 \mathrm{~K}, 313 \mathrm{~K}, 328 \mathrm{~K}$, and $343 \mathrm{~K}$.

\begin{tabular}{|c|c|c|c|c|c|c|}
\hline \multirow{2}{*}{ T (K) } & \multirow{2}{*}{ BiasP \% } & \multirow{2}{*}{ MRDP \% } & \multirow{2}{*}{ BiasY \% } & \multirow{2}{*}{ MRDY \% } & \multicolumn{2}{|c|}{ Van Ness Test } \\
\cline { 5 - 7 } & & & & & $\Delta \mathbf{y}$ & $\Delta$ \\
\hline \hline 298.00 & 0.65 & -0.65 & -0.77 & 0.77 & 0.96 & 0.77 \\
\hline 313.01 & -0.04 & 0.04 & 0.13 & -0.13 & 0.51 & 0.83 \\
\hline 327.98 & -0.05 & 0.05 & 0.36 & -0.36 & 0.62 & 0.57 \\
\hline 342.98 & 0.72 & -0.72 & 0.71 & -0.71 & 0.75 & 0.47 \\
\hline
\end{tabular}

As suggested by Boonaert et al. [8], the van Ness test [31] is a good way to check the consistency of the experimental measurement. This test is defined following Eqs. 8 and 9. The test consists of the estimation of vapor molar fraction and pressure deviations.

$$
\begin{aligned}
& \Delta \mathrm{P}=\frac{100}{N} \sum\left|\frac{P_{\text {exp }}-P_{\text {cal }}}{P_{\text {cal }}}\right| \\
& \Delta \mathrm{y}=\frac{100}{N} \sum\left|y_{\text {exp }}-y_{\text {cal }}\right|
\end{aligned}
$$

To pass the van Ness test, $\Delta \mathrm{P}$ and $\Delta y$ must be lower than 1. In Table 6, the results of the test are available. We can see that our data passes the van Ness test. This result, therefore, also validates the consistency of our data.

As there is no data in the open literature for comparison with our results, we have considered the VLE predictions obtained with the two most popular predictive models: PPR78 [11] and PSRK UNIFAC [12]. The MRDU and the biasU between our data and predictions for the two predictive models are presented in Table 7. We can observe a relatively good agreement between the predicted and experimental data. The best predictions are obtained with the PRSK UNIFAC model.

\section{Conclusion}

For this study, an experimental technique based on the static-analytic method was used to measure new VLE data of the isobutane and ethyl mercaptan binary system. The experimental work was carried out between 298 and $343 \mathrm{~K}$ and up to $1 \mathrm{MPa}$ at the temperature and pressure range of the process of natural gas fractionation systems. The relative volatility and the van Ness test were used to check the quality and the consistency of the experimental data. The measured data were also compared to the predictions of two predictive models, and a good agreement was observed using the PSRK UNIFAC and PPR78 models. 
Table 7: MRDU (from Eq 6) and BiasU (from Eq 7) between the VLE isobutane + ethyl mercaptan data and the two predictive models: PPR78 and PSRK, at 298 K, 313 K, $328 \mathrm{~K}$ and $343 \mathrm{~K}$.

\begin{tabular}{|c|c|c|c|c|}
\hline $\mathbf{T}(\mathrm{K})$ & BiasP \% & MRDP \% & Biasy \% & MRDy \% \\
\hline \multicolumn{5}{|c|}{ PPR78 EOS } \\
\hline 298.00 & -9.27 & 9.27 & -8.78 & 8.78 \\
\hline 313.01 & -5.19 & 5.19 & -4.10 & 4.10 \\
\hline 327.98 & -3.73 & 3.73 & -1.54 & 1.54 \\
\hline 342.98 & -1.98 & 1.98 & -0.62 & 0.62 \\
\hline \multicolumn{5}{|c|}{ PSRK EOS } \\
\hline 298.00 & 5.72 & -5.72 & 3.61 & -3.61 \\
\hline 313.01 & 4.27 & -4.27 & 4.37 & -4.37 \\
\hline 327.98 & 3.22 & -3.22 & 2.30 & -2.30 \\
\hline 342.98 & 1.81 & -1.81 & 1.56 & -1.56 \\
\hline
\end{tabular}

\section{Nomenclature}

\section{Latin letters}

F: objective function

k: binary interaction parameter

$\mathrm{n}$ : number of moles (mol)

$\mathrm{N}$ : number of data

$\mathrm{P}$ : pressure $(\mathrm{Pa})$

$\mathrm{T}$ : temperature $(\mathrm{K})$

u: uncertainty

$\mathrm{U}$ : pressure $(\mathrm{P})$ or gaseous molar fraction $(\mathrm{y})$

$\mathrm{x}$ : molar fraction

$y:$ gaseous molar fraction

\section{Greek letters}
a: relative volatility
$\omega:$ acentric factor

\section{Subscript}

c: critical

cal: calculated

calib: calibrated

exp: experimental

$\mathrm{i}$ : component $\mathrm{i}$

$\mathrm{j}$ : component $\mathrm{j}$

rep: repeatability 


\section{References}

[1] Kohl A, Nielsen R. Gas purification 5th ed. Houst Gulf Publ Co 1997.

[2] Stewart M, Arnold K. Gas sweetening and processing field manual. Gulf Professional Publishing; 2011.

[3] Speight JG. Handbook of petroleum product analysis. John Wiley \& Sons; 2015.

[4] Breysse M, Djega-Mariadassou G, Pessayre S, Geantet C, Vrinat M, Pérot G, et al. Deep desulfurization: reactions, catalysts and technological challenges. Catal Today 2003;84:129-38. https://doi.org/10.1016/S0920-5861(03)00266-9.

[5] van Konynenburg PH, Scott RL, Rowlinson JS. Critical lines and phase equilibria in binary van der Waals mixtures. Philos Trans R Soc Lond Ser Math Phys Sci 1980;298:495-540. https://doi.org/10.1098/rsta.1980.0266.

[6] Afzal W, Valtz A, Coquelet C. Vapour-Liquid Equilibria of Ethane and Ethanethiol: Experiments and Modelling. J Nat Gas Eng 2018;3:96108. https://doi.org/10.7569/jnge.2018.692505.

[7] Awan JA, Tsivintzelis I, Coquelet C, Kontogeorgis GM. Phase Equilibria of Three Binary Mixtures: Methanethiol + Methane, Methanethiol + Nitrogen, and Methanethiol + Carbon Dioxide. J Chem Eng Data 2012;57:896-901. https://doi.org/10.1021/je2011049.

[8] Boonaert E, Valtz A, Coquelet C. Vapour-liquid equilibria of n-butane and ethyl mercaptan: Experiments and modelling. Fluid Phase Equilibria 2020;504:112335. https://doi.org/10.1016/j.fluid.2019.112335.

[9] Awan JA, Coquelet C, Tsivintzelis I, Kontogeorgis G. Phase Equilibrium Measurements and Modeling of 1-Propanethiol+ 1-Butanethiol+ CH4 in Methane Ternary System at 303, 336, and $368 \mathrm{~K}$ and Pressure Up to 9 MPa. J Chem Eng Data 2016;61:41-4. https://doi.org/10.1021/acs.jced.5b00134.

[10] Robinson DB, Peng D-Y. The characterization of the heptanes and heavier fractions for the GPA Peng-Robinson programs. Gas processors association; 1978.

[11] Privat R, Mutelet F, Jaubert J-N. Addition of the hydrogen sulfide group to the PPR78 model (predictive 1978, Peng-Robinson equation of state with temperature dependent $\mathrm{k}$ ij calculated through a group contribution method). Ind Eng Chem Res 2008;47:10041-52. https://doi.org/10.1021/ie800799z.

[12] Horstmann S, Fischer K, Gmehling J. PSRK group contribution equation of state: revision and extension III. Fluid Phase Equilibria 2000;167:173-86. https://doi.org/10.1016/S0378-3812(99)00333-7.

[13] ThermoLit: NIST Literature Report Builder for Thermochemical Property Measurements. NIST Lit Rep Draft n.d. https://trc.nist.gov/thermolit/main/home.html\#draft/report (accessed June 2, 2021).

[14] Lobo LQ, Ferreira AGM, Fonseca IMA, Senra AMP. Vapour pressure and excess Gibbs free energy of binary mixtures of hydrogen sulphide with ethane, propane, and n-butane at temperature of 182.33K. J Chem Thermodyn 2006;38:1651-4. https://doi.org/10.1016/j.jct.2006.03.013.

[15] Robinson DB, Hughes RE, Sandercock J a. W. Phase behavior of the n-butane-hydrogen sulphide system. Can J Chem Eng 1964;42:1436. https://doi.org/10.1002/cjce.5450420402.

[16] Leu AD, Robinson DB. Equilibrium phase properties of the $n$-butane-hydrogen sulfide and isobutane-hydrogen sulfide binary systems. J Chem Eng Data 1989;34:315-9. https://doi.org/10.1021/je00057a017.

[17] Dicko M, Coquelet C, Theveneau P, Mougin P. Phase Equilibria of H2S-Hydrocarbons (Propane, n-Butane, and n-Pentane) Binary Systems at Low Temperatures. J Chem Eng Data 2012;57:1534-43. https://doi.org/10.1021/je300111m.

[18] Zudkevitch D, Wilson G. Phase equilibria in solutions of methyl mercaptan and light hydrocarbons, Denver, Colorado, USA: 1974, p. 101-3.

[19] Giles NF, Wilson GM. Phase Equilibria on Seven Binary Mixtures. J Chem Eng Data 2000;45:146-53. https://doi.org/10.1021/je990221o.

[20] Giles NF, Wilson LC, Wilson GM, Wilding WV. Phase Equilibria on Eight Binary Mixtures. J Chem Eng Data 1997;42:1067-74. https://doi.org/10.1021/je970028z.

[21] Valtz A, Guilbot P, Richon D. Vapor-Liquid Equilibria for Volatile Sulfur-containing Systems. III. Butane - Sulfur Compounds Containing Systems. IV. Hydrocarbon - Hydrocarbon - Sulfur Compounds Containing Systems. V. Hydrocarbon - Hydrogen Sulfide Compounds Containing Systems. Gas Processors Association; 1998.

[22] Penttilä A, Uusi-Kyyny P, Pokki J-P, Pakkanen M, Alopaeus V. Isothermal Binary Vapor-Liquid Equilibrium for 2-Methylpropane and nButane with 1,2-Ethanedithiol and 2-Methyl-2-propanethiol. J Chem Eng Data 2010;55:291-6. https://doi.org/10.1021/je9003417.

[23] Haimi P, Uusi-Kyyny P, Pokki J-P, Pakkanen M, Aittamaa J, Keskinen KI. Isothermal binary vapour-liquid equilibrium for butanes and butenes with dimethylsulphide. Fluid Phase Equilibria 2008;266:143-53. https://doi.org/10.1016/j.fluid.2008.01.030.

[24] Uusi-Kyyny P, Sapei E, Pokki J-P, Pakkanen M, Alopaeus V. Vapor-Liquid Equilibrium for Dimethyl Disulfide + Butane, + trans-But-2-ene, + 2-Methylpropane, + 2-Methylpropene, + Ethanol, and 2-Ethoxy-2-methylpropane. J Chem Eng Data 2011;56:2501-10. https://doi.org/10.1021/je200039y.

[25] Besserer GJ, Robinson DB. The equilibrium phase properties of the i-butane-hydrogen sulfide system. J Chem Eng Jpn 1975;8:11-5. https://doi.org/10.1252/jcej.8.11.

[26] Brooks FR, Nixon AC. Boiling Point and Composition of Methanethiol-Isobutane Azeotrope. J Am Chem Soc 1953;75:480-480. https://doi.org/10.1021/ja01098a502. 
[27] Zhang F, Théveneau P, El Ahmar E, Canet X, Soo C-B, Coquelet C. An improved static-analytic apparatus for vapor-liquid equilibrium (PTxy) measurement using modified in-situ samplers. Fluid Phase Equilibria 2016;409:425-33. https://doi.org/10.1016/j.fluid.2015.10.041.

[28] Théveneau P, Valtz A, Coquelet C. Vapor Liquid Equilibrium Data for the Furan-Toluene Binary System between 313.02 and 352.99 K. J Chem Eng Data 2017;62:1168-72. https://doi.org/10.1021/acs.jced.6b00424.

[29] Théveneau P, Legendre H. Dispositif pour prélever des micro-échantillons d'un fluide à l'état liquide contenu dans un containeur. FR1460309, 2016.

[30] Mathias PM. Guidelines for the Analysis of Vapor-Liquid Equilibrium Data. J Chem Eng Data 2017;62:2231-3. https://doi.org/10.1021/acs.jced.7b00582.

[31] van Ness HC, Byer SM, Gibbs RE. Vapor-Liquid equilibrium: Part I. An appraisal of data reduction methods. AIChE J 1973;19:238-44. https://doi.org/10.1002/aic.690190206. 